has the movement been along certain lines, that the bands of greywacke and shale have been intensely crumpled and puckered, and have actua'ly been converted locally into fine micaceous schists.

Hence it seems tolerably certain that though in the west of Ireland the chief plications, fractures, and metamorphism were completed before Upper Silurian time, and though a vast interval must have elapsed during which the progress of denudation laid bare the younger schists, and thereby provided materials for the Upper Silurian conglomerates, the terrestrial disturbances nevertheless continued during the deposition of these conglomerates, and were renewed with increased vigour afterwards.

If we compare the geological structure of the Silurian tracts of England, Wales, and the south of Scotland, and the east of Ireland, with that of the areas of the younger crystalline schists, many points of resemblance will be seen to occur between them. Towards the north and north-west we find that the Archæan, Cambrian, and oldest Silurian rocks, now exposed there by the progess of denudation, have been subjected to the intensest mechanical deformation, and have assumed the most completely schistose structures. Coming southward, we trace the younger crystalline schists of the Central Highlands and of Donegal thrown into innumerable north-east and south-west folds, and becoming less and less metamorphosed as they are followed towards the lower grounds. Still further south the Lower and Upper Silurian rocks, plicated, crumpled, and dislocated, repeat the familiar structure of the Southern Highlands, but with only partial and feeble metamorphism. I am disposed to look upon the whole of these structures as the result of one great succession of terrestrial movements which began and reached their maximum of intensity during some part of Lower Silurian time, but which continued to repeat themselves at intervals with greater or less vigour through a long series of geological ages, down to the early part of the Old Red Sandstone period.

As the consequence of this prolonged disturbance, the Archæan and older Palæozoic rocks have been thrown into those north-east and south-west folds, which have in large part determined the trend of the land in the north-west of Europe. The shaping of our mountains into their present forms has been brought about by ages of subsequent sculpture, in which the agencies employed by Nature have operated mainly on the surface, but the carving of their features has been guided by the internal structures developed by those subterranean movements which we have been considering.

\section{THE ENTIRE SKELETON OF AN ENGLISH DINOSAUR.}

SOME years ago an article appeared in the columns of this journal (vol. xxviii. p. 439), in which a notice was given of the marvellously preserved skeletons of Iguanodon from the Wealden deposits of Bernissart, in Belgium, some of which are now exhibited in the Brussels Museum of Natural History. In that article the author very properly insisted upon the extreme importance of those specimens from an anatomical point of view, as exhibiting the whole of the bones of the skeleton in their natural juxtaposition. He was, however, probably then unaware (as the undermentioned specimen was not at that time exhibited to the public) that the British Museum possessed the skeleton of an English Dinosaur, which, although of smaller size than the Bernissart Iguanodons, belongs to the same sub-ordinal group, and exhibits equally clearly the mutual relations of the component bones. The English skeleton is, indeed, in some respects much more satisfactory than the Belgian specimens, inasmuch as its bones have not been flattened and crushed in the manner which so sadly disfigures those of the latter. Further, the English Dinosaur has an additional interest in that it is one of quite the earlier members of the group, its geological horizon being the Lower Lias of Dorsetshire.

This specimen, as being the only known example of the almost entire skeleton of a Dinosaur from English deposits, is so remarkable as to deserve especial attention from all those interested in the former inhabitants of our islands. In the first place, the history of its discovery is somewhat curious. Thus, some time previously to I $86 \mathrm{I}, \mathrm{Mr}$. J. Harrison, of Charmouth, obtained from the Lower Lias of that neighbourhood portions of the hind-limb of a comparatively large Dinosaur, and, later on, a skull, lacking only the extremity of the muzzle. In the year mentioned, these specimens were described by Sir Richard Owen in the publications of the Palæontographical Society, under the name of Scelidosaurus harrisoni; the portions of the limb being taken as the type of the genus, and the skull referred to a smaller individual of the same species. Stimulated by the extreme interest aroused by the discovery of this skull, Mr. Harrison continued his excavations on the spot where the latter had been obtained, and was rewarded by finding the whole of the remainder of the skeleton, with the unfortunate exception of most of the vertebra of the neck. The skeleton was extracted in several blocks, and these, after careful "development" of the bones, were fitted together so as to enable the whole skeleton to be exhibited.

Until the completion of the Natural History Museum at South Kensington, this magnificent skeleton was, however, from want of space, never exhibited to public view; and it was not until some three years ago that it was properly mounted and placed in its present position, where, in a handsome glass case which permits a view of both sides, it forms one of the chief treasures of the unrivalled gallery of fossil reptiles in that Museum. The bones being all firmly cemented together by matrix, and aiso more or less dislocated out of their normal places, it was, however, of course impossible to mount the skeleton in its natural position - which was probably a semi-erect one; and it is accordingly now placed with the axis of the vertebral column in a horizontal position. As thus mounted, the specimen is about I I feet in length, but the absence of the cervical vertebrie renders it impossible to ascertain its true dimensions, the head being now placed much too near to the shoulder-girdle. The skeleton has been somewhat dislocated, and twisted over to the right side, so that the neural arches and spines of the vertebræ of the back and loins are seen on the right, and the under surface of their bodies, or centra, on the left side of the specimen. Both hind-limbs are entire, although the left one is thrust up by the twist, and has become placed near the tail. The haunch-bones (ilia) of the pelvis still nearly retain their normal position; and on the left side of the specimen we see the lower extremities of the left pubis and ischium Iying crossed over the lower ends of the corresponding bones of the right side. A portion of that part of the pubis which lies in advance of the acetabulum is visible; and the post-acetabular portions of both the pubis and ischium lie in the original parallel position which is so characteristic of this group of Dinosaurs and of the Struthious birds. The left side of the shoulder-girdle is well preserved, and has the humerus and portions of the bones of the fore-arm in their original position; but the bones of the hands are wanting. The dermal scutes, with which the body and tail were protected, are seen arranged in longitudinal rows, which have, however, been somewhat thrown out from their original position. We would especially call the attention of those who may think it worth their while to visit the Museum, in order to study this unique specimen, to the marvellous preservation of the hind-limbs, which permits even the smallest bones of the toes to be 
fully exhibited on both sides. It may, however, be worth the consideration of the authorities of the Museum, whether this skeleton might not be more easily understood by the uninitiated if the various bones were labelled with their scientific, and perhaps also with their popular, names, since it is somewhat puzzling, even to the expert, to name them all at a glance.

As already mentioned, the skull of the skeleton was figured by Sir R. Owen in $186 \mathrm{I}$, and the acquisition of the remainder of the skeleton enabled that eminent palæontologist to confirm his reference of the skull to the genus Scelidosaurus. The body-skeleton formed, indeed, the subject of a second memoir published by the Palæontographical Society in I862, with eleven quarto plates; but we venture to say that these illustrations do not render justice to the specimen, since they only include separate portions. To fully illustrate this unrivalled skeleton would, indeed, require a double quarto plate, in which the whole specimen should be shown, with the individual bones duly labelled; and a task thus remains for some zealous palæontologist to fulfil.

The accompanying figure is an attempt at a restoration of the skeleton in the natural position of the animal.
The presence of a predentary bone in advance of the mandibular symphysis is based on the occurrence of this element in Iguanodon and the allied Stegosaurus; while the five digits in the hand are likewise introduced from the evidence of the latter genus.

The importance of this specimen is that it is the only English Dinosaur, with the exception of the small Hypsilophodon, which shows all the bones of the skeleton in position; and although it is of course exceedingly easy to be wise after the event, yet we cannot help thinking that this skeleton might have afforded its describer the opportunity of being the first to determine the true nature and position of the bones of the pelvis in this group of Dinosaurs-a problem which was solved in a paper communicated to the Geological Society in 1876 . The two parallel bones lying on the inferior aspect of the hinder part of the trunk of this specimen, and directed backwardly, could not, indeed, possibly have been taken for anything else but the pubis and ischium; and the resemblance of the latter bone to the problematical "os cuvieri," or so-called clavicle, of Mantell's imperfect skeleton of Iguanodon, which has for many years been in the Museum, might have suggested the homology of

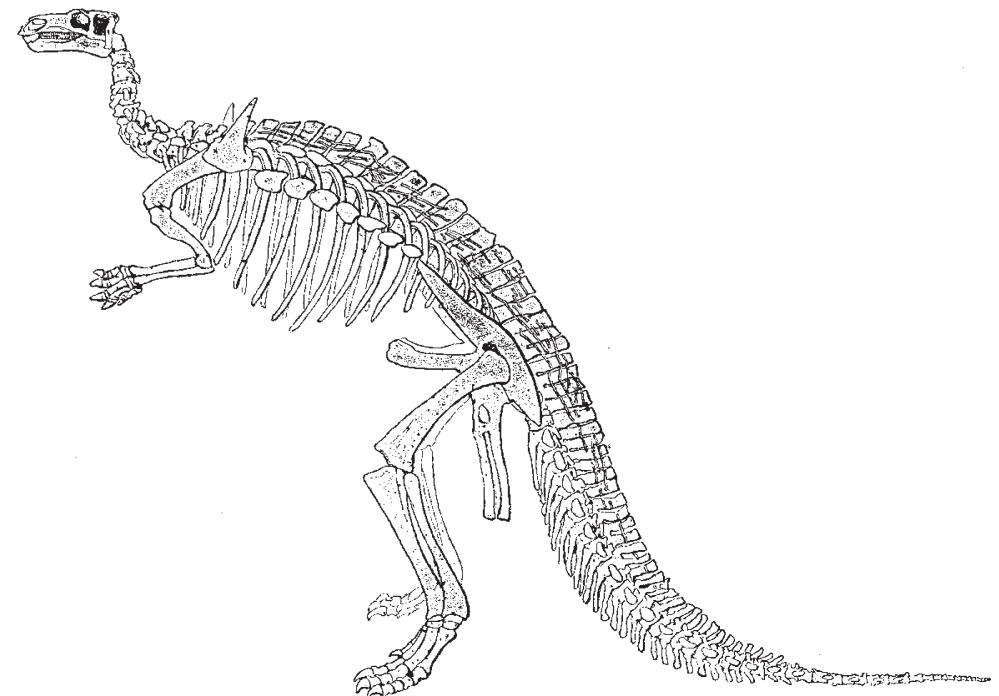

Approximate restoration of the skeleton of Srelidosaurus harrisoni, frem the I.ower Lias of Charmsuth. Greatly reduced. The vertebral column has been restored from Iguanodon, and the spines and chevrons of the vertebræare, nut improbably, too long: the ossified tendons are conjectural.

the two bones. Curiously enough, however, the pubis and ischium, which are certainly the most remarkable bones in the whole skeleton, are not figured, and apparently not even mentioned, in the original memoir.

Finally, it may perhaps interest some of our readers who do not follow the ever-changing classifications of the palæontologists, to mention that the genus Scelidosaurus is the type of a family referred by Prof. O. C. Marsh to his sub-order Stegosauria. Other authorities, however, consider that this sub-order is not really separable from the Ornithopoda of the same writer, which includes the Iguanodons. Accepting this emendation, the Ornithopoda will be a sub-order of Dinosauria, including all those forms in which the pelvis has a structure comparable to that of the Struthious birds ; while the remaining members of that order may be classed in the sub-order Theropoda, as represented by Megalosaurus, and the Sauropoda, as represented by Cetiosaurus and Pelorosaurus. Recently, indeed, it has been proposed to abolish the name Dinosauria, and to group the Theropoda and Sauropoda together under the new name of Saurischia, and to apply the name Ornithischia to the
Ornithopoda. The name Dinosauria has, however, become such a household word, that its suppression cannot be admitted ; and if it be eventually found advisable to adopt the proposed division of these reptiles into two distinct orders, the preferable course would be to restrict the name Dinosauria to the so-called Saurischia, since Megalosaurus and Cetiosuurus were the forms first mentioned in the original notice of the order in 1840 ; while the earlier names, such as Ornithopoda, might be retained for the second order. In this connection we may, however, quote a remark made by an eminent man of science at a meeting of the Geological Society, to the effect that "he was inclined to think that the progress of knowledge tended rather to break down the lines of demarcation between groups supposed to be distinct, than to authorize the creation of fresh divisions."

R. L.

\section{NOTES}

WE print elsewhere the Technical Instruction Bill introduced into the House of Commons last week by Sir W. Hart Dyke. The Government is to be congratulated on having presented a 